\title{
ПРОФИЛАКТИКА СИНДРОМА ЭМОЦИОНАЛЬНОГО ВЫГОРАНИЯ У ПРЕПОДАВАТЕЛЕЙ ГУМАНИТАРНЫХ ВЫСШИХ УЧЕБНЫХ ЗАВЕДЕНИЙ
}

Н. В. Полунина, Л. С. Солтамакова $\bowtie$

Кафедра общественного здоровья и здравоохранения, экономики здравоохранения,

Российский национальный исследовательский университет имени Н. И. Пирогова, Москва

\begin{abstract}
Профессиональная деятельность преподавателей сопряжена с воздействием большого числа стресс-факторов, которые могут проявляться на работе, во взаимоотношениях с начальством, напряженной обстановкой в коллективе, вследствие различных социально-психологических переживаний на работе и дома. Длительное воздействие этих факторов способствует развитию синдрома эмоционального выгорания, профилактика которого просто необходима. Целью исследования было выявить симптомы синдрома эмоционального выгорания у преподавателей гуманитарных высших учебных заведений и разработать мероприятия по его профилактике. Обследовано 1489 преподавателей гуманитарных вузов с помощью составленных анонимных анкет для изучения профессиональной деятельности педагогов, а также выборочных карт на основании листков нетрудоспособности. Для статистического анализа рассчитывали средние величины и их ошибки, интенсивные и экстенсивные показатели; использовали метод сравнения относительных величин и определение достоверности различия. Выявлено, что у двух преподавателей из трех присутствуют чувство усталости, частые боли в спине и груди, головная боль. В результате балльной оценки степени выраженности данных симптомов обнаружено, что большая часть преподавателей (43,2\%) оказалась в группе с высоким уровнем психоэмоционального выгорания. У каждого второго преподавателя наблюдается низкий уровень медицинской активности. Для профилактики синдрома эмоционального выгорания необходимо внедрение мероприятий, направленных на формирование позитивной медицинской активности, повышение медицинской грамотности и воспитание навыков здорового образа жизни.
\end{abstract}

Ключевые слова: преподаватель, синдром эмоционального выгорания, профессиональная деятельность, медицинская активность, просилактика

$\checkmark$ Для корреспонденции: Лиана Солтамаковна Солтамакова ул. Островитянова, д. 1, г. Москва, 117997; 06doctor06@mail.ru

Статья получена: 05.08.2018 Статья принята к печати: 26.10.2018

DOI: $10.24075 /$ vrgmu.2018.059

\section{PREVENTION OF STAFF BURNOUT IN HUMANITIES TEACHERS OF HIGHER EDUCATIONAL INSTITUTIONS}

Polunina NV, Soltamakova LS $\bowtie$

Department of Public Health, Healthcare and Healthcare Economics,

Pirogov Russian National Research Medical University, Moscow

\begin{abstract}
In their daily life teachers go through a lot of stress ensuing from abrasive relationships with the administrative staff, colleagues or students, and family conflicts. Long-term exposure to stressors leads to the syndrome of emotional burnout, which can be avoided is preventive care is taken. The aim of this study was to identify burnout symptoms in the humanities teachers working for higher educational institutions and to propose adequate preventive measure. We recruited 1,489 teachers who were offered to anonymously fill out a questionnaire and also collected information about their health from sickness leaves. Statistical analysis included calculation of means, their errors, intensive and extensive variables, and confidence intervals. Two in three teachers reported fatigue, regular back/chest pain, and headache. The use of a scoring scale allowed us to conclude that a lot of respondents (43.2\%) had severe burnout symptoms. Every second teacher demonstrated poor health awareness. To prevent staff burnout, measures should be taken aimed at stimulating a positive attitude to medical care, improving health literacy and motivating teachers to lead a healthy lifestyle.
\end{abstract}

Keywords: teacher, staff burnout, professional occupation, health awareness, prevention

$\triangle$ Correspondence should be addressed: Liana S. Soltamakova

Ostrovityanova 1, Moscow, 117997; 06doctor06@mail.ru

Received: 05.08.2018 Accepted: 26.10.2018

DOI: 10.24075/brsmu.2018.059

Особенности выполняемой работы в той или иной мере отражаются на состоянии здоровья и образе жизни человека [1-3]. Следует учитывать, что профессиональная деятельность сказывается не только на здоровье человека, но и на образе его жизни, особенностях мышления, характере поведения. Значительное число работ по изучению профессиональной деятельности работающего населения и анализу воздействия профессиональных факторов риска на здоровье работающих показывает, что необходима разработка мероприятий по профилактике возникающих отклонений в здоровье [4-6].

Особое внимание в публикуемых работах уделено изучению информационных нагрузок на здоровье работников умственного труда. Выполненные исследования доказывают, что их наличие способствует развитию стрессобусловленных заболеваний $[7,8]$. Например, рассмотрены 
проблемы, связанные с физиолого-гигиенической оценкой информационных нагрузок при создании оптимальных условий труда [9]. Предложены алгоритмы оптимизации интеллектуального труда методами визуализации информации с помощью когнитивной семантической графики [10].

Ряд исследований посвящен изучению здоровья и профессиональной деятельности учителей. Отмечено, что значительная часть учителей имеет хронические заболевания, но лишь два человека из троих состоят на диспансерном учете [11, 12]. Среди хронических заболеваний преобладают гипертоническая болезнь, хронический ларинготрахеит, заболевания вен нижних конечностей, среди острых заболеваний - острые респираторные заболевания, ларингиты и ларинготрахеиты. Многие из них в определенной степени обусловлены профессиональной деятельностью, связанной с большой голосовой нагрузкой, существенным психоэмоциональным напряжением

Профессия педагога сопряжена с воздействием комплекса фракторов, обусловленных взаимоотношениями с учащимися, необходимостью направить их деятельность на изучение нового материала, на освоение определенных навыков. Работа педагога относится к группе профессий, предметом которых является другой человек, педагог помимо профессиональных знаний управляет процессом интеллектуального и эмоционального развития обучающегося, формируя у него духовный мир. Основное содержание педагогической профессии составляют взаимоотношения с людьми, умение понять и направить усилия других людей на достижение целей, поставленных государством и обществом [13].

Современный преподаватель, независимо от вида выполняемой им работы, имеет постоянные стрессовые ситуации, обусловленные решением проблем при взаимодействии с руководством и коллегами по работе, со студентами. Социально-психологические переживания и состояния могут затрагивать разные грани трудового процесса: профессиональную деятельность, личность профессионала, профессиональное общение, в целом отрицательно сказываются на профессиональном развитии личности. Именно работа с людьми, предъявляющая высокие требования не только к профессиональным, но и к социально-психологическим знаниям, обеспечивающим взаимоотношения с коллегами и руководством, с учащимися и их родственниками, содержитв себевысокие риски тяжелых переживаний, связанных непосредственно с рабочими моментами, что в дальнейшем увеличивает вероятность появления симптомов эмоционального выгорания.

Синдром эмоционального выгорания (СЭВ) это реакция организма, возникающая вследствие продолжительного воздействия профессиональных стрессов средней интенсивности. Термин «эмоциональное выгорание» был использован в 1974 г. американским психиатром Х. Дж. Фрейденбергером для характеристики психологического состояния здоровых людей, находящихся в интенсивном и тесном общении с клиентами и пациентами с эмоционально неустойчивой психикой. Синдром выгорания рассматривался им как сложный психофизиологический феномен, и включал эмоциональное, умственное и физическое истощение, что проявлялось в наличии депрессивного состояния, чувства усталости и опустошенности, в недостатке энергии и энтузиазма, утрате способностей видеть положительные результаты своего труда, отрицательной установке в отношении работы и жизни вообще $[14,15]$. Социальный психолог K. Maslac описала этот синдром как синдром физического и эмоционального истощения, включая развитие отрицательной самооценки, отрицательного отношения к работе, утрату понимания и сочувствия по отношению к клиентам и пациентам. СЭВ - это механизм психологической защиты в форме полного или частичного исключения эмоций в ответ на избирательные психотравмирующие воздействия [16].

В то же время в опубликованных материалах не нашла своего отражения характеристика СЭВ у преподавателей высших учебных заведений, не раскрыты причины его возникновения и не показана роль в формировании неблагоприятных показателей здоровья. Целью данного исследования было выявить и изучить симптомы СЭВ у преподавателей гуманитарных высших учебных заведений, а также предложить мероприятия по их профилактике.

\section{ПАЦИЕНТЫ И МЕТОДЫ}

Для изучения проявлений симптомов СЭВ и его влияния на здоровье было обследовано 1489 преподавателей гуманитарных вузов. Критерии включения: мужчины и женщины в возрасте от 25 лет; стаж работы в вузе 5 лет и более. Для изучения профессиональной деятельности, морально-психологического климата и проявлений СЭВ была составлена анкета, включающая 85 вопросов. Анкеты были анонимными, что позволяло собрать наиболее объективную информацию, и заполнялись в электронном виде. Для изучения состояния здоровья были составлены выборочные карты, которые заполнялись на основании листков нетрудоспособности. Сбор анкет и выборочных карт осуществлялся непосредственно после их заполнения, чтобы обеспечить максимальную возвратность. Статистическая обработка собранного материала включала вычисление средних величин и их ошибок, интенсивных и экстенсивных показателей, их ошибок, метод сравнения относительных величин и определение достоверности различия, коэффициент корреляции по методу Пирсона.

\section{РЕЗУЛЬТАТЫ ИССЛЕДОВАНИЯ}

Среди педагогов высших учебных заведений наиболее распространены такие симптомы СЭВ, как наличие постоянного чувства усталости, головной боли и боли в спине и груди, в появлении лишнего веса, снижении работоспособности, памяти и внимания, нарушения сна (табл. 1).

В среднем у одного преподавателя имеет место 4-5 симптомов, характеризующих эмоциональное выгорание. Наиболее часто, почти у каждого второго преподавателя, имеются жалобы на постоянное чувство усталости, головную боль, лишний вес и нарушение сна.

Все симптомы, характеризующие СЭВ, оценивались преподавателями в зависимости от степени их выраженности от 0 (при отсутствии симптома) до 5 (при выраженности симптомов) баллов: минимальное число - 6 баллов, максимальное - 40 баллов. В зависимости от суммы полученных баллов провели оценку симптомов СЭВ. Все преподаватели были разделены на 3 группы: в группу с низким уровнем психоэмоционального выгорания вошли те преподаватели, которые получили от 0 до 12 баллов, в группу с высоким 
уровнем психоэмоционального выгорания вошли все получившие от 27 до 40 баллов, группу со средним уровнем психоэмоционального выгорания составили преподаватели с суммой баллов от 13 до 26 (табл. 2).

Нередко появлению перечисленных симптомов СЭВ предшествует наличие у пациента ряда признаков неблагоприятного психоэмоционального состояния. Почти у каждого второго преподавателя (46,8\% преподавателей) имеют место эмоциональная лабильность и изменчивость настроения, снижение внимания, раздражительность и немотивированная тревожность. Каждый третий преподаватель жалуется на плохое самочувствие. В среднем у одного участника исследования выявлено 1-2 симптома, характеризующих неблагоприятное психоэмоциональное состояние.

Сравнительный анализ результатов анкетирования показал, что педагоги с высоким уровнем выраженности СЭВ достоверно чаще жалуются на наличие неблагоприятных симптомов психоэмоционального состояния (табл. 3).

Анализ показал, что среди преподавателей преобладают женщины $(67,4 \%)$ со средним возрастом 51,4 \pm 0,7 лет, при этом удельный вес педагогов в возрасте до 40 лет составил 28,7\%, старше 60 лет - 31,7\%. Общий педагогический стаж работы в среднем составил 23,1 \pm 0,4 года, в том числе до 10 лет - 24,2\% опрошенных, более 30 лет - 36,4\%. Большинство преподавателей $(62,4 \%)$ имеет такой стаж работы в одном учреждении.

Отмечено, что среди преподавателей в возрасте старше 60 лет в сравнении с педагогами до 40 лет достоверно чаще встречаются симптомы СЭВ. Сравнительный анализ показал, что среди преподавателей старших возрастных групп достоверно чаще в 2,8-2,4 раза отмечены такие симптомы, как сонливость в дневное время, боли в спине и груди, снижение памяти и внимания, постоянное чувство усталости и появление лишнего веса (табл. 4).

Анализ наличия симптомов СЭВ у преподавателей высших учебных заведений в зависимости от стажа работы в качестве преподавателя показал прямую корреляционную зависимость между ними ( $r=0,576$; $m= \pm 0,034 ; p<0,05)$. Отмечено, что у лиц со стажем работы свыше 30 лет в сравнении с педагогами, имеющими педагогический стаж работы до 10 лет, достоверно $(p<0,05)$ чаще имеют место те же симптомы СЭВ, что и у лиц старших возрастных групп (табл. 5).

Помимо проявлений симптомов СЭВ у обследованных преподавателей были проанализированы характеристики сложившегося морально-психологического климата в семье и на работе.

При изучении факторов, оказывающих влияние на формирование СЭВ, установлено, что наличие неблагоприятного морально-психологического климата в семье и на работе способствует развитию высокого уровня эмоционального выгорания. При оценке моральнопсихологического климата были учтены такие компоненты, как наличие в анамнезе тяжелых переживаний, сложившиеся взаимоотношения на работе с коллегами и учащимися и в семье между супругами и родственниками.

Отмечено, что в целом у каждого преподавателя в прошлом были моменты, которые способствовали созданию в их окружении неблагоприятного моральнопсихологического климата. Наиболее часто участники

Таблица 1. Распространенность симптомов СЭВ у преподавателей гуманитарных высших учебных заведений

\begin{tabular}{|c|l|c|}
\hline \multicolumn{1}{|c|}{ Симптомы, характеризующие СЭВ } & Число случаев на 100 опрошенных \\
\hline 1 & \multicolumn{1}{|c|}{ С/п } & 67,4 \\
\hline 2 & Постоянное чувство усталости & 64,2 \\
\hline 3 & Боль в спине и груди & 62,4 \\
\hline 4 & Головная боль & 58,1 \\
\hline 5 & Появление лишнего веса & 53,2 \\
\hline 6 & Снижение работоспособности & 50,9 \\
\hline 7 & Нарушения сна & 49,5 \\
\hline 8 & Снижение памяти и внимания & \\
\hline
\end{tabular}

Таблица 2. Распределение преподавателей гуманитарных вузов на группы по оценке уровня выраженности симптомов СЭВ

\begin{tabular}{|l|c|c|}
\hline Оценка уровня эмоционального выгорания & Число баллов & Число баллов, \% \\
\hline Низкий & до 12 & 39,4 \\
\hline Средний & $13-26$ & 37,4 \\
\hline Высокий & $27-40$ & 43,2 \\
\hline Итого & & 100 \\
\hline
\end{tabular}

Таблица 3. Распространенность симптомов психоэмоционального состояния у преподавателей гуманитарных вузов (на 100 опрошенных)

\begin{tabular}{|c|c|c|c|c|}
\hline \multirow{3}{*}{$\begin{array}{c}\text { Симптомы, характеризующие } \\
\text { психоэмоциональное состояние }\end{array}$} & \multicolumn{3}{|c|}{ На 100 преподавателей } & \multirow{3}{*}{$\begin{array}{c}\text { Вероятность безошибочного } \\
\text { прогноза } p\end{array}$} \\
\hline & \multirow{2}{*}{ в целом } & \multicolumn{2}{|c|}{ Оценка эмоционального выгорания } & \\
\hline & & низкий уровень & высокий уровень & \\
\hline Эмоциональная лабильность & 39,3 & 29,8 & 38,8 & $<0,01$ \\
\hline Изменчивость настроения & 37,3 & 27,2 & 37,4 & $<0,01$ \\
\hline Сниженная концентрация внимания & 32,1 & 23,9 & 30,3 & $<0,05$ \\
\hline Раздражительность & 29,7 & 19,9 & 29,5 & $<0,01$ \\
\hline Немотивированная тревожность & 24,2 & 15,9 & 22,5 & $<0,05$ \\
\hline Плохое самочувствие & 29,1 & 21,7 & 26,5 & $>0,05$ \\
\hline
\end{tabular}


исследования отмечали наличие конфликтных отношений в семье, в том числе между супругами, и с родственниками. На работе у каждого пятого преподавателя возникали неблагоприятные взаимоотношения с коллегами, руководством и учащимися. Обращает на себя внимание тот факт, что каждый пятый преподаватель в качестве неблагоприятного фактора отметил наличие у себя тяжелого заболевания (табл. 6).

Сравнительный анализ показал, что преподаватели, имеющие высокий уровень проявления СЭВ, достоверно чаще имели признаки неблагоприятного моральнопсихологического климата в сравнении с преподавателями с низким уровнем проявления СЭВ (табл. 6).

Все выше перечисленное способствует увеличению нервно-психического напряжения и ухудшению здоровья преподавателя.

СЭВ - сложный психофизиологический феномен, который определяется как эмоциональное, умственное и физическое истощение, что проявляется в чувстве усталости, в развитии депрессивного состояния, в утрате способности видеть положительные результаты своего труда, отрицательной установке в отношении работы и жизни вообще.

Для устранения неблагоприятных факторов эмоционального выгорания необходимо уметь переключаться с профессиональной деятельности на любые другие виды деятельности, не связанные с выполнением профессиональных обязанностей.

Результаты опроса преподавателей выявили, что значительная часть из них имеют недостаточную физическую активность и погрешности в питании, не соблюдают режим питания (питаются нерегулярно), не считают необходимым следить за своим весом, а для нормализации сна нередко прибегают к употреблению лекарственных препаратов по собственному усмотрению (табл. 7). Обращает на себя внимание тот факт, что несмотря на наличие СЭВ у значительной части преподавателей гуманитарных вузов к врачу обращается лишь каждый четвертый преподаватель, а выполняют его рекомендации только 39,6 преподавателей из 100 опрошенных.

В среднем на одного преподавателя приходится 4,27 \pm 0,32 отрицательных признаков проявления медицинской активности; среди преподавателей с высокой степенью выраженности СЭВ выявлено 4,96 \pm 0,35 негативных проявлений медицинской активности, а в группе с низкой степенью достоверно меньше $(p<0,01)$ отрицательных признаков $(3,12 \pm 0,31)$.

Сравнительный анализ медицинской активности преподавателей с различной степенью выраженности СЭВ (табл. 7) показал, что преподаватели с высоким уровнем эмоционального выгорания достоверно чаще (в 3,1 раза) не обращаются к врачу при нарушении здоровья, в 1,9 раза чаще имеют более низкую продолжительность ночного сна, в 1,7 раза чаще принимают лекарства без назначения врача, в 1,5 раза чаще не контролируют свой вес и не считают нужным это делать, в 1,4 раза чаще ведут малоподвижный образ жизни, не удовлетворены ночным отдыхом, не выполняют рекомендации врача.

В группу с низкой медицинской активностью были включены преподаватели, имеющие шесть и более негативных признаков медицинской активности. Среди преподавателей с высокой степенью выраженности СЭВ 68,5\% имели низкую медицинскую активность, а среди преподавателей с низким уровнем эмоционального выгорания таковых было в 1,9 раза больше, что свидетельствует о необходимости изменения характера медицинского поведения.

\section{ОБСУЖДЕНИЕ РЕЗУЛЬТАТОВ}

Проведенное исследование позволило изучить проявления СЭВ у преподавателей гуманитарных высших учебных заведений. Установлено, что примерно у двух преподавателей из трех имеют место постоянное чувство

Таблица 4. Наличие симптомов СЭВ у преподавателей гуманитарных высших учебных заведений по возрастным группам

\begin{tabular}{|c|l|c|c|c|}
\hline \multirow{2}{*}{$\begin{array}{c}\text { № } \\
\text { п/п }\end{array}$} & \multirow{2}{*}{ Симптомы, характеризующие СЭВ } & \multicolumn{2}{|c|}{ Число случаев на 100 опрошенных } & \multirow{2}{*}{ Вероятность безошибочного прогноза $p$} \\
\cline { 3 - 4 } & & Возраст до 40 лет & Возраст более 60 лет & $<0,01$ \\
\hline 1 & Постоянное чувство усталости & 36,5 & 86,3 & $<0,01$ \\
\hline 2 & Боль в спине и груди & 32,1 & 84,3 & $<0,05$ \\
\hline 3 & Головная боль & 42,9 & 69,9 & $<0,01$ \\
\hline 4 & Появление лишнего веса & 29,7 & 74,5 & $<0,05$ \\
\hline 5 & Снижение работоспособности & 33,8 & 60,6 & $<0,05$ \\
\hline 6 & Нарушения сна & 34,9 & 54,9 & $<0,01$ \\
\hline 7 & Снижение памяти и внимания & 24,3 & 62,7 & $<0,01$ \\
\hline 8 & Сонливость днем & 21,6 & 60,6 & \\
\hline
\end{tabular}

Таблица 5. Наличие симптомов СЭВ у преподавателей гуманитарных высших учебных заведений в зависимости от стажа работы

\begin{tabular}{|c|l|c|c|c|}
\hline \multirow{2}{*}{$\begin{array}{c}\text { № } \\
\text { п/п }\end{array}$} & \multirow{2}{*}{ Симптомы, характеризующие СЭВ } & \multicolumn{2}{|c|}{ Число случаев на 100 обследованных } & \multirow{2}{*}{ Вероятность безошибочного прогноза $p$} \\
\cline { 3 - 4 } & & Стаж до 10 лет & Стаж более 30 лет & \\
\hline 1 & Постоянное чувство усталости & 29,2 & 90,6 & $<0,001$ \\
\hline 2 & Боль в спине и груди & 27,9 & 85,5 & $<0,001$ \\
\hline 3 & Головная боль & 34,1 & 75,7 & $<0,05$ \\
\hline 4 & Появление лишнего веса & 19,6 & 81,6 & $<0,001$ \\
\hline 5 & Снижение работоспособности & 32,8 & 58,6 & $<0,05$ \\
\hline 6 & Нарушения сна & 35,1 & 51,7 & $<0,05$ \\
\hline 7 & Снижение памяти и внимания & 23,4 & 60,6 & $<0,01$ \\
\hline 8 & Сонливость днем & 21,8 & 57,4 & $<0,01$ \\
\hline
\end{tabular}


усталости, частые боли в спине и груди, головная боль. Это способствует снижению работоспособности, памяти и внимания. Отмечено, что нередко у преподавателей имеют место нарушение ночного сна и появление сонливости в дневное время. Как правило, у преподавателей с перечисленными симптомами в 58,1\% случаев появляется лишний вес.

Использование балльной оценки степени выраженности изученных симптомов, характеризующих синдром эмоционального выгорания, дало возможность распределить обследованных преподавателей на три группы. В группу с высоким уровнем выраженности СЭВ вошли преподаватели, получившие от 27 до 40 баллов, группу с низким уровнем выраженности СЭВ составили преподаватели, получившие от 0 до 12 баллов. K сожалению, большая часть преподавателей (43,2\%) отнесена в группу с высоким уровнем психоэмоционального выгорания и только каждый пятый - в группу с низким уровнем психоэмоционального выгорания.

Изучение социально-психологической характеристики преподавателей гуманитарных вузов выявило, что среди обследованного контингента преобладают женщины со средним возрастом 51,4 \pm 0,7 лет, с общим педагогическим стажем работы 23,1 \pm 0,4 года, большинство преподавателей работают на протяжении всей трудовой жизни в одном и том же образовательном учреждении. Установлено, что СЭВ чаще наблюдается у преподавателей старше 60 лет и имеющих стаж работы в образовательном учреждении более 30 лет.

Помимо возраста и стажа работы на формирование СЭВ оказывает влияние неблагоприятный моральнопсихологический климат в семье и в трудовом коллективе. Исследование морально-психологического климата показало, что у каждого преподавателя в прошлом были моменты, которые можно расценивать как неблагоприятный морально-психологический климат, однако сравнительный анализ показал, что среди преподавателей с выраженным СЭВ достоверно чаще выявлены неблагоприятные характеристики морально-психологического климата в сравнении с преподавателями с низкой степенью выраженности СЭВ.

Особого внимания заслуживает изучение медицинской активности преподавателей. Полученные результать свидетельствуют, что практически у каждого второго преподавателя уровень медицинской активности оценен как низкий. При этом среди преподавателей с выраженным СЭВ достоверно чаще в сравнении с преподавателями с низким уровнем эмоционального выгорания признаки медицинской активности имеют отрицательный характер: преподаватели чаще ведут малоподвижный образ жизни, нарушают режим питания и сна, не обращаются к врачу и не выполняют его рекомендации, принимают лекарственные препараты по своему усмотрению, страдают избыточным весом.

Учитывая, что наличие СЭВ, который служит признаком эмоционального, умственного и физического истощения организма, способствует ухудшению здоровья, при осуществлении профилактических мероприятий необходимо, с одной стороны, максимально нивелировать влияние негативных факторов, а с другой - повысить уровень медицинской активности преподавателей. Тем более, что при опросе преподавателей выявлены их недостаточная медицинская грамотность о факторах риска для здоровья (69,7\%), отсутствие мотивации к здоровому образу жизни $(47,2 \%)$, знаний о роли ночного отдыха (46,2\%), двигательной активности (43,1\%), нарушения режима питания $(39,7 \%)$, отсутствие своевременного обращения к врачу $(39,6 \%)$ и выполнения его рекомендаций $(34,1 \%)$ для устранения неблагоприятных факторов.

Профилактическая работа с преподавателями должна проводиться в амбулаторно-поликлинических учреждениях и вестись в трех направлениях. Необходимы меры, направленные, во-первых, на повышение медицинской грамотности; во-вторых, на повышение мотивации к правильному медицинскому поведению; в-третьих, на формирование навыков позитивной медицинской активности.

Таблица 6. Распределение обследуемых преподавателей по наличию признаков неблагоприятного морально-психологического климата (на 100 человек)

\begin{tabular}{|c|c|c|c|c|c|}
\hline \multirow{2}{*}{$\begin{array}{c}\text { № } \\
\Pi / \text { ח }\end{array}$} & \multirow{2}{*}{ Характеристики морально-психологического климата } & \multirow{2}{*}{$\begin{array}{l}\text { Число случаев } \\
\text { на } 100 \text { человек }\end{array}$} & \multicolumn{2}{|c|}{ Оценка эмоционального выгорания } & \multirow{2}{*}{$\begin{array}{c}\text { Вероятность } \\
\text { безошибочного } \\
\text { прогноза } p\end{array}$} \\
\hline & & & Высокий уровень & Низкий уровень & \\
\hline 1 & Частые конфликтные ситуации с мужем/женой & 25,5 & 36,2 & 14,7 & $<0,01$ \\
\hline 2 & Частые конфликтные ситуации с близкими родственниками & 24,7 & 36,4 & 12,9 & $<0,01$ \\
\hline 3 & Частые конфликтные ситуации с коллегами и руководством & 21,6 & 29,2 & 13,9 & $<0,01$ \\
\hline 4 & Частые конфликтные ситуации со студентами & 21,2 & 31,9 & 10,4 & $<0,01$ \\
\hline 5 & Неудовлетворительное состояние здоровья & 20,8 & 32,7 & 8,9 & $<0,01$ \\
\hline 6 & Тяжелое заболевание или смерть близкого человека & 15,2 & 18,6 & 11,8 & $<0,05$ \\
\hline
\end{tabular}

Таблица 7. Распределение обследуемых преподавателей по показателям медицинской активности (на 100 человек)

\begin{tabular}{|c|c|c|c|c|c|}
\hline \multirow{2}{*}{$\begin{array}{c}\text { № } \\
\Pi / \Pi\end{array}$} & \multirow{2}{*}{ Показатели медицинской активности } & \multirow{2}{*}{ В целом } & \multicolumn{2}{|c|}{ Оценка СЭВ } & \multirow{2}{*}{$\begin{array}{c}\text { Вероятность безошибочного } \\
\text { прогноза } p\end{array}$} \\
\hline & & & Высокий уровень & Низкий уровень & \\
\hline 1 & Малоподвижный образ жизни & 64,9 & 72,1 & 52,7 & $<0,01$ \\
\hline 2 & Нарушение питания (режим и погрешности) & 57,1 & 66,4 & 42,8 & $<0,01$ \\
\hline 3 & Отсутствие контроля за массой тела & 56,4 & 64,9 & 42,9 & $<0,01$ \\
\hline 4 & Неудовлетворенность ночным отдыхом & 54,7 & 60,7 & 43,7 & $<0,01$ \\
\hline 5 & Нежелание нормализовать свой вес & 47,3 & 54,7 & 34,9 & $<0,01$ \\
\hline 6 & Низкая продолжительность ночного сна & 46,8 & 58,2 & 30,4 & $<0,01$ \\
\hline 7 & Выполнение рекомендаций врача & 39,6 & 43,6 & 30,6 & $<0,01$ \\
\hline 8 & Употребление лекарств для нормализации ночного сна & 37,2 & 44,1 & 25,3 & $<0,05$ \\
\hline 9 & Обращение к врачу в связи с нарушениями здоровья & 23,4 & 31,7 & 10,1 & $<0,01$ \\
\hline
\end{tabular}


Поскольку значительную роль в развитии СЭВ играет психоэмоциональное состояние, целесообразно привлекать психолога для работы с преподавателями высших учебных заведений.

\section{ВЫВОДЫ}

Более половины преподавателей гуманитарных высших учебных заведений имеют симптомы СЭВ, в том числе испытывают постоянное чувство усталости, жалуются на частые головные боли и боли в груди, отмечают снижение работоспособности и памяти. К факторам, способствующим формированию СЭВ, следует отнести неблагоприятный морально-психологический климат в рабочем коллективе и дома, а также неблагоприятное психоэмоциональное состояние. Преподаватели с выраженными симптомами СЭВ имеют низкий уровень проявления медицинской активности, в том числе несвоевременно обращаются к врачу, не выполняют его рекомендации, нарушают режим сна и питания, недостаточно физически активны и используют лекарства без назначения врача. В целях профилактики развития СЭВ необходимо проведение мероприятий, направленных на повышение медицинской активности преподавателей, в том числе на повышение медицинской грамотности и развитие мотивации к правильному медицинскому поведению.

\section{Литература}

1. Пиктушанская И. Н. О состоянии профессиональной заболеваемости и инвалидности вследствие профзаболеваний, качестве периодических медицинских осмотров в Ростовской области. Информационный сборник статистических, аналитических и нормативных материалов. Ростов-на-Дону, 2002; 28 c.

2. Пахомов В. Ф. Анализ профессиональной заболеваемости в отрасли от воздействия вибрации. Рекомендации по снижению заболеваемости вибрационной болезнью в отрасли и переводу рабочих виброопасных профессий на другие виды работ. М.: НИАТ, 1987; 3-12.

3. Измеров Н. Ф., Денисов Э. И., редакторы. Руководство. Профессиональный риск для здоровья работников. М.: Тровант, 2003; 448 с.

4. Измеров Н. Ф., Денисов Э. И., Прокопенко Л. В., Сивочалова О. В., Степанян И. В., Челищева М. Ю. и др. Методология выявления и профилактики заболеваний, связанных с работой. Медицина труда и промышленная экология. 2010; (9): $1-7$

5. Научный совет № 45 «Медико-экологические проблемь здоровья работающих» РАМН 13 мая 2010 г. Методические рекомендации. Методология выявления и просилактики заболеваний, связанных с условиями труда. М.: НИИ МТ PAMH, 2010; 24 c.

6. Прокопенко Л. В., Кравченко О. К., Костенко Н. А., Кириллов В. Ф. Просилактика неблагоприятного воздействия виброакустических факторов в современных условиях. Актуальные проблемы «Медицины труда». Сборник трудов института. Под редакцией академика РАН Н. Ф. Измерова и профессора И. В. Бухтиярова. 2015: 68-70.

\section{References}

1. Piktushanskaja IN. O sostojanii professional'noj zabolevaemosti invalidnosti vsledstvie profzabolevanij, kachestve periodicheskih medicinskih osmotrov $v$ Rostovskoj oblasti. Informacionnyj sbornik statisticheskih, analiticheskih i normativnyh materialov. Rostov-na-Donu, 2002; 28 s.

2. Pahomov VF. Analiz professional'noj zabolevaemosti $v$ otrasli ot vozdejstvija vibracii. Rekomendacii po snizheniju zabolevaemosti vibracionnoj bolezn'ju v otrasli i perevodu rabochih vibroopasnyh professij na drugie vidy rabot. M.: NIAT, 1987; 3-12.

3. Izmerov NF, Denisov Jel, redaktory. Rukovodstvo. Professional'ny] risk dlja zdorov'ja rabotnikov. M.: Trovant, 2003; 448 s.

4. Izmerov NF, Denisov Jel, Prokopenko LV, Sivochalova OV, Stepanjan IV, Chelishheva MJu i dr. Metodologija vyjavlenija i profilaktiki zabolevanij, svjazannyh s rabotoj. Medicina truda promyshlennaja jekologija. 2010; (9): 1-7.

5. Nauchnyj sovet \# 45 «Mediko-jekologicheskie problemy zdorov'ja rabotajushhih» RAMN 13 maja 2010 g. Metodicheskie

7. Бухтияров И. В. Основы информационной гигиены: концепции и проблемы инноваций. Гигиена и санитария. 2014; (4): 5-9.

8. Денисов Э. И. Информация как физический фактор: проблемы измерения, гигиенической оценки и ИТавтоматизации. Медицина труда и промышленная экология. 2014; (1): 36-43

9. Еремин А. Л. Проблема физиолого-гигиенической оценки инсормационных нагрузок для оптимизации труда [диссертация]. М., 2014.

10. Степанян И. В. Алгоритмы оптимизации интеллектуального труда методами визуализации информации с помощью когнитивной семантической графики. Нейрокомпьютеры: разработка и применение. 2014; (7): 53-9.

11. Ильченко Ю. Г. Гигиеническая оценка состояния здоровья учителей средних общеобразовательных учреждений [диссертация]. Ростов-на-Дону, 2006; 25 с.

12. Мухтарова Л. Р. Комплексная оценка влияния факторов внешней и внутренней среды на состояние здоровья учителей (на примере г. Липецка) [диссертация]. М., 2005.

13. Косарев И. И., Шурупова Р. В. Кто должен обучать студентов. Сеченовский вестник. 2014; 1 (15): 99-101.

14. Пеникер О. В. Синдром профессионального выгорания и его профилактика. Психология. Труды СГА. 2008; (11): 32-40.

15. Скугаревская М. М. Синдром эмоционального выгорания. Медицинские новости. 2002; (7): 3-9.

16. Королева Е. Г., Щустер Э. И. Синдром эмоционального выгорания. Журнал ГрГМУ. 2007; (3): 108-11.

rekomendacii. Metodologija vyjavlenija i profilaktiki zabolevanij, svjazannyh s uslovijami truda. M.: NII MT RAMN, 2010; 24 s.

6. Prokopenko LV, Kravchenko OK, Kostenko NA, Kirillov VF. Profilaktika neblagoprijatnogo vozdejstvija vibroakusticheskih faktorov v sovremennyh uslovijah. Aktual'nye problemy «Mediciny truda». Sbornik trudov instituta. Pod redakciej akademika RAN NF. Izmerova i professora IV. Buhtijarova. 2015: 68-70.

7. Buhtijarov IV. Osnovy informacionnoj gigieny: koncepcii i problemy innovacij. Gigiena i sanitarija. 2014; (4): 5-9.

8. Denisov Jel. Informacija kak fizicheskij faktor: problemy izmerenija, gigienicheskoj ocenki i IT-avtomatizacii. Medicina truda i promyshlennaja jekologija. 2014; (1): 36-43.

9. Eremin AL. Problema fiziologo-gigienicheskoj ocenki informacionnyh nagruzok dlja optimizacii truda [dissertacija]. M., 2014.

10. Stepanjan IV. Algoritmy optimizacii intellektual'nogo truda metodami vizualizacii informacii s pomoshh'ju kognitivnoj 
semanticheskoj grafiki. Nejrokomp'jutery: razrabotka i primenenie. 2014; (7): 53-9.

11. II'chenko JuG. Gigienicheskaja ocenka sostojanija zdorov'ja uchitelej srednih obshheobrazovatel'nyh uchrezhdenij [dissertacija]. Rostov-na-Donu, 2006; 25 s.

12. Muhtarova LR. Kompleksnaja ocenka vlijanija faktorov vneshnej vnutrennej sredy na sostojanie zdorov'ja uchitelej (na primere g. Lipecka) [dissertacija]. M., 2005.
13. Kosarev II, Shurupova R. V. Kto dolzhen obuchat' studentov. Sechenovskij vestnik. 2014; 1 (15): 99-101.

14. Peniker OV. Sindrom professional'nogo vygoranija i ego profilaktika. Psihologija. Trudy SGA. 2008; (11): 32-40.

15. Skugarevskaja MM. Sindrom jemocional'nogo vygoranija. Medicinskie novosti. 2002; (7): 3-9.

16. Koroleva EG, Shhuster Jel. Sindrom jemocional'nogo vygoranija. Zhurnal GrGMU. 2007; (3): 108-11. 